\title{
HOXA11 hypermethylation is associated with progression of non-small cell lung cancer
}

\author{
Jung-Ah Hwang ${ }^{1}$, Bo Bin Lee ${ }^{2}$, Yujin Kim², Seong-Eun Park², Kyun Heo ${ }^{1}$, Seung- \\ Hyun Hong ${ }^{1}$, Young-Ho Kim³ ${ }^{3}$, Joungho Han ${ }^{4}$, Young Mog Shim ${ }^{5}$, Yeon-Su Lee ${ }^{1}$, and \\ Duk-Hwan Kim² \\ ${ }^{1}$ Cancer Genomics Branch, Research Institute, National Cancer Center, Goyang-si, Korea \\ 2 Department of Molecular Cell Biology, Samsung Biomedical Research Institute, Sungkyunkwan University School of \\ Medicine, Suwon, Korea \\ ${ }^{3}$ Department of Internal Medicine, Samsung Medical Center, Sungkyunkwan University School of Medicine, Seoul, Korea \\ ${ }^{4}$ Department of Pathology, Samsung Medical Center, Sungkyunkwan University School of Medicine, Seoul, Korea \\ ${ }^{5}$ Department of Thoracic and Cardiovascular Surgery, Samsung Medical Center, Sungkyunkwan University School of \\ Medicine, Seoul, Korea \\ Correspondence to: Yeon-Su Lee, email: yslee2@ncc.re.kr
}

Duk-Hwan Kim, email: dukhwan.kim@samsung.com

Keywords: HOXA1 1; Hypermethylation; Non-small cell lung cancer; Progression; Migration

Received: October 3, $2013 \quad$ Accepted: October 27, $2013 \quad$ Published: October 28, 2013

This is an open-access article distributed under the terms of the Creative Commons Attribution License, which permits unrestricted use, distribution, and reproduction in any medium, provided the original author and source are credited.

ABSTRACT:

This study was aimed at understanding the functional significance of HOXA11 hypermethylation in non-small cell lung cancer (NSCLC). HOXA11 hypermethylation was characterized in six lung cancer cell lines, and its clinical significance was analyzed using formalin-fixed paraffin-embedded tissues from 317 NSCLC patients, and Ki-67 expression was analyzed using immunohistochemistry. The promoter region of HOXA11 was highly methylated in six lung cancer cell lines, but not in normal bronchial epithelial cells. The loss of expression was restored by treatment of the cells with a demethylating agent, 5-aza-2'-deoxycytidine (5-Aza-dC). Transient transfection of HOXA11 into H23 lung cancer cells resulted in the inhibition of cell migration and proliferation. HOXA11 hypermethylation was found in $218(69 \%)$ of 317 primary NSCLCs. HOXA11 hypermethylation was found at a higher prevalence in squamous cell carcinoma than in adenocarcinoma ( $74 \%$ vs. $63 \%$, respectively). HOXA11 hypermethylation was associated with Ki-67 proliferation index $(P=0.03)$ and pT stage $(P=0.002)$, but not with patient survival. Patients with pT2 and pT3 stages were 1.85 times $(95 \%$ confidence interval $[\mathrm{CI}]=1.04-3.29 ; P=0.04)$ and 5.47 times $(95 \%$ CI $=1.18-25.50 ; P=0.01)$, respectively, more likely to show HOXA11 hypermethylation than those with pT1 stage, after adjusting for age, sex, and histology. In conclusion, the present study suggests that HOXA11 hypermethylation may contribute to the progression of NSCLC by promoting cell proliferation or migration.

\section{INTRODUCTION}

Lung cancer is currently the leading cause of cancerrelated deaths worldwide despite significant strides in its early detection and treatment over the past few decades; the overall 5-year survival rate remains low at $10 \%-15 \%$ [1]. Micrometastasis, which has occurred in over two- thirds of patients at diagnosis, along with the high rate of recurrence after resection, is mainly responsible for the poor prognosis of lung cancer patients. Even those patients with stage 1 lung cancer detected prior to the spread of the cancer to other nearby lymph nodes and sites still suffer from poor prognosis [2]. Hence, it is vital to develop biomarkers to be used for the identification of patients 
with a relatively high risk of poor prognosis and for the early detection and targeted therapy. Over the past few years, several epigenetic biomarkers have been developed with this goal in mind.

$H O X$ genes encode transcription factors that play essential roles in embryonic development and differentiation of adult cells. $H O X$ genes are also known to play an essential role in lung development and are expressed in the normal human adult lung [3]. $H O X$ genes in mammals are arranged into clusters $(\mathrm{A}, \mathrm{B}, \mathrm{C}$, and D) on four different chromosomes [4]. The $H O X A$ cluster, located within a $155-\mathrm{kb}$-long genomic region on chromosome $7 \mathrm{p} 15-7 \mathrm{p} 14.2$ consists of 12 genes (11 $H O X$ genes and EVX1) [5]. Highly dense CpG islands are prevalent in most of the $H O X A$ promoters and the hypermethylation of these islands play pivotal roles in the control of $H O X A$ gene expression. Among $H O X \mathrm{~A}$ genes, $H O X A 11$ hypermethylation has recently been reported in lung cancer [6-8], ovarian cancer $[9,10]$, glioblastoma multiforme [11], follicular lymphoma [12], endometrial adenocarcinoma [13] and cervical cancer [14]. Nonetheless, the clinicopathological significance of its methylation remains to be uncovered for lung cancer, and $H O X A 11$ hypermethylation is currently a target of active research.

To gain better insight into the role of HOXA11 gene in NSCLCs, we characterized the HOXA11 hypermethylation in vitro and further investigated the association between clinicopathological parameters and HOXA11 hypermethylation in paraffin-embedded tissues from 317 primary non-small cell lung cancers (NSCLCs).

\section{RESULTS}

\section{Methylation analysis of HOXA11 promoter in vitro}

The locations of CpGs that were analyzed using EpiTYPER $^{\mathrm{TM}}, \mathrm{MS}-\mathrm{HRM}$, and MSP are indicated in Figure 1A. The HOXA11 promoter sequence was obtained from Transcription Element Search System (http://www.cbil. upenn.edu/cgi-bin/tess/tess), and methylation statuses of $90 \mathrm{CpGs}$ at the promoter region of HOXA11 were first analyzed quantitatively using the EpiTYPER ${ }^{\mathrm{TM}}$; some of the CpGs were partially methylated in H23, H520, and H1650 cells (Fig. 1B). HOXA11 expression, analyzed using quantitative real-time PCR (Fig. 1C) and western blotting (Fig. 1D), correlated well with these methylation statuses. The mRNA and protein levels of six lung cancer cell lines were downregulated compared to HBE135-E6E7 bronchial epithelial cells, except weak expression in H460. This result suggests that $H O X A 11$ hypermethylation may be responsible for silencing of HOXA11.

\section{5-Aza-dC induced demethylation and re- expression of silenced $\mathrm{HOXA11}$}

Dependence of the downregulation of HOXA11 in lung cancer cells on hypermethylation of the gene


D

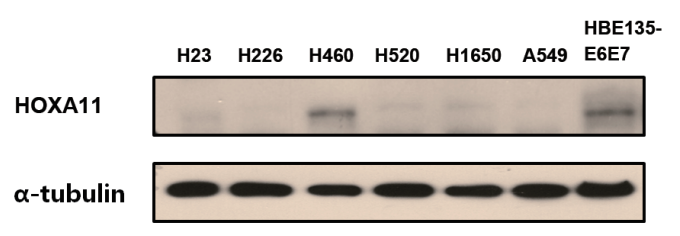

Figure 1: Analysis of the methylation and expression of $\mathrm{HOXA11}$ in vitro. (A) Gene map shows location of $\mathrm{CpGs}$ that were studied by different methods in this study. (B) The methylation status of $90 \mathrm{CpGs}$ at the promoter region of HOXA11 was analyzed using the EpiTYPER ${ }^{\mathrm{TM}}$ assay in six lung cancer cell lines (H23, H226, H460, H520, H1650, and A549), a bronchial epithelial cell line (HBE135-E6E7), and in a normal human dermal fibroblast (HDF). Two-way cluster analysis shows the methylation status of HOXA11 in eight cell lines. Levels of methylation are depicted in color change on a continuous scale from red ( $0 \%$ methylated) to light yellow ( $100 \%$ methylated). X-axis and Y-axis indicate $\mathrm{CpG}$ sites and cell lines, respectively. (C \& D) The mRNA levels of HOXA11 were analyzed by real-time PCR (C), and protein levels were determined using western blotting (D). Error bars indicate one standard deviation. 
was validated by analyzing the re-expression and demethylation of silenced genes using RT-PCR (Fig. 2A), quantitative real-time PCR (Fig. 2B), MS-HRM assay (Fig. 2C), and EpiTYPER ${ }^{\mathrm{TM}}$ (Fig. 2D), after treatment of lung cancer cells with $10 \mu \mathrm{M} 5$-Aza-dC for $72 \mathrm{~h}$. Reexpression of HOXA11 (Figs. 2A and 2B) in response to 5-Aza-dC was minimal in H226 and A549 cells, but other cell lines showed a substantial increase at the mRNA levels of $H O X A 11$. The degree of demethylation after treatment of 5-Aza-dC was also minimal in H226 and A549 cells (Fig. 2C). Figure 2D shows a typical pattern of demethylation: demethylation occurred much more in H460 cells with less densely methylated CpGs than in A549 cells with densely methylated CpGs, suggesting that the degree of demethylation in response to 5-Aza$\mathrm{dC}$ may be inversely related to the density of initial hypermethylation. Because histone deacetylase inhibitor is known to cooperate for re-expression of hypermethylated genes, the H226 and A549 cells showing minimal reexpression of silenced $H O X A 11$ in response to 5-Aza$\mathrm{dC}$ were further co-incubated with 5-Aza-dC for another $24 \mathrm{~h}$ in the presence of $0.5 \mu \mathrm{M}$ TSA following $48 \mathrm{~h}$ of initial 5-Aza-dC treatment. TSA along with 5-Aza-dC in $\mathrm{H} 226$ and A549 cells induced reactivation of the silenced
HOXA11 at the level of mRNA by RT-PCR (Fig. 2E) and real-time PCR (Fig. 2F).

\section{HOXA11 inhibited cell migration and proliferation in lung cancer cells}

To investigate the function of $H O X A 11$ in tumorigenesis, cell migration and cell proliferation was analyzed in $\mathrm{H} 23$ cells induced by transient transfection of GFP-tagged $H O X A 11$. Anti-GFP antibody was used to detect the expression of HOXA11 (Fig. 3A) by western blot analysis. Cell migration was significantly reduced in H23 cells transfected with pAcGFP-HOXA11 construct $(\mathrm{P}=0.01$; Fig. 3B). Cell proliferation was also analyzed in the H23 cells after transfection of the GFP-fusion constructs. Cell proliferation was inhibited in $\mathrm{H} 23$ cells induced by pAcGFP-HOXA11 (Fig. 3C): pAcGFPHOXA11 suppressed cell proliferation by $30 \%$ at $72 \mathrm{~h}$ after seeding the cells for MTT assay. Based on these observations, it is likely that $H O X A 11$ may function as a tumor suppressor by inhibiting cell migration and cell proliferation in tumorigenesis of the lung.

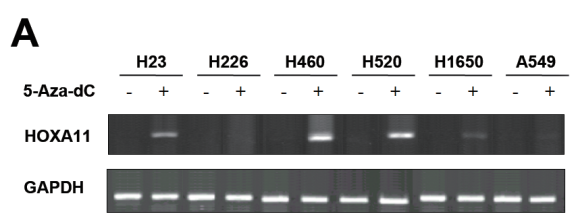

B

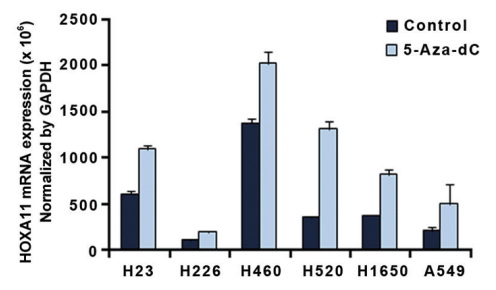

C
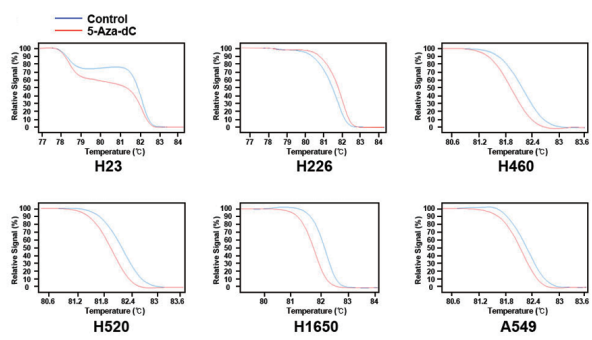

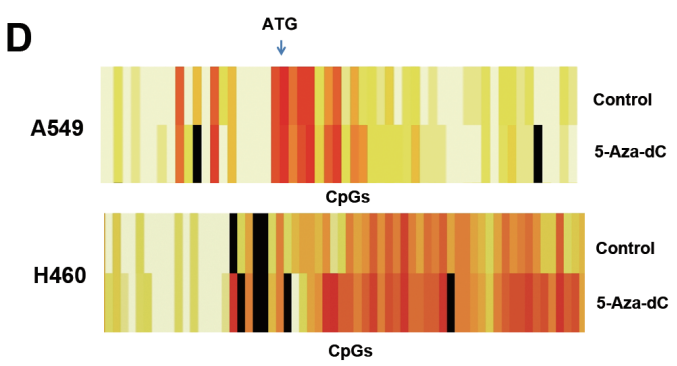

E

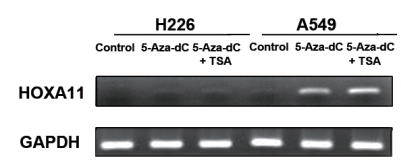

$\mathbf{F}$

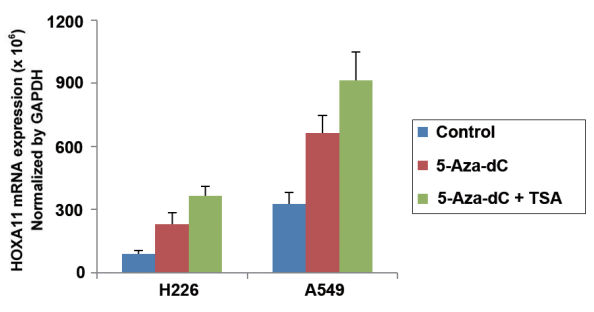

Figure 2: Effects of 5-Aza-dC and/or TSA on demethylation and re-expression of silenced $H O X A 11$. (A \& $\mathrm{B}$ ) Reexpression of silenced HOXA11 was examined by RT-PCR (A) and real-time PCR (B) in six lung cancer cell lines after treatment of the cells with 5-Aza-dC for $72 \mathrm{~h}$. Compared to other cell lines, re-expression of HOXA11 is minimal in H226 and A549 cells. Plus and minus signs indicate the presence or absence of 5-Aza-dC treatment, respectively. (C) Demethylation of silenced HOXA11 was analyzed using MS-HRM assay after treatment of 5-Aza-dC for $72 \mathrm{~h}$ in 6 lung cancer cell lines. Red and blue lines indicate the statuses with and without treatment of 5-Aza-dC, respectively. (D) Heatmaps show typical patterns of demethylation: the degree of demethylation is high in H460 cells with less densely methylated HOXA11 and minimal in A549 cells with densely methylated HOXA11. (E \& F) H226 and A549 cells that showed minimal re-expression of HOXA11 were treated with $10 \mathrm{M} 5$-Aza-dC in combination with $0.5 \mathrm{M}$ TSA for $72 \mathrm{~h}$. TSA induced additional re-expression of HOXA11 by RT-PCR (E) and real-time PCR (F). Error bars indicate one standard deviation. 


\section{Association of $\mathrm{HOXA11}$ hypermethylation with clinicopathological variables in primary NSCLCs}

In order to understand the clinicopathological significance of HOXA11 hypermethylation, we analyzed the methylation status of HOXA11 using methylationspecific PCR (Fig. 4A) and the Ki-67 proliferation

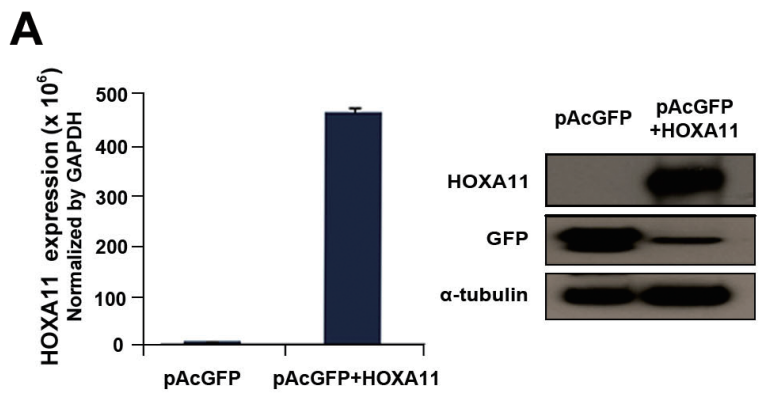

B

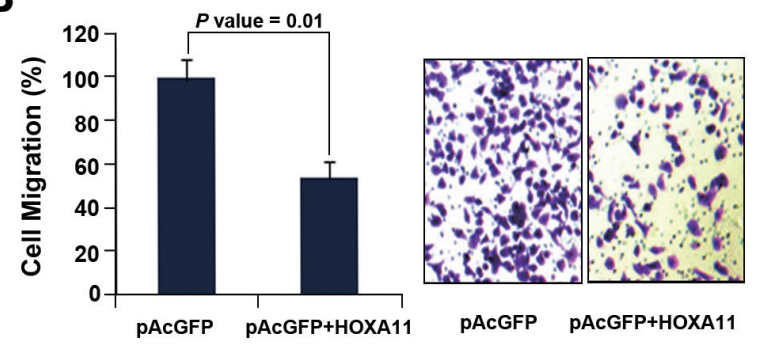

C

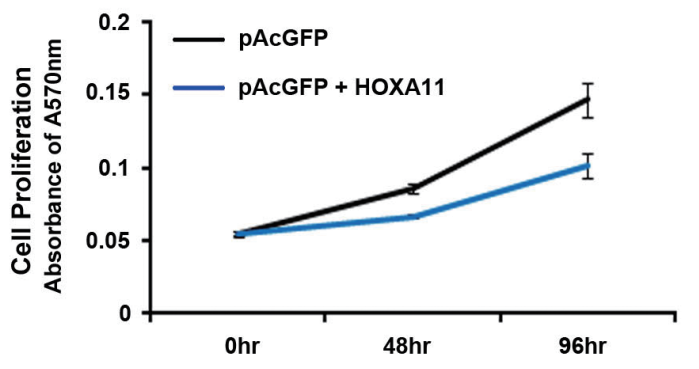

Figure 3: The effect of $H O X A 11$ on cell migration and proliferation. (A) To analyze the effect of HOXA11 on cell migration and proliferation, $\mathrm{H} 23$ lung cancer cells were transfected with pAcGFP-HOXA11 fusion construct, or empty vector. After transfection, the expression of HOXA11 was confirmed by western blot using primary antibody directed to GFP (sc-9996; Santa Cruz Biotechnology, CA, USA). (B) H23 cells transfected with pAcGFP-HOXA11 were re-seeded in $6.5 \mathrm{~mm}$ Transwell ${ }^{\circledR}$ with $8 \mu \mathrm{m}$ pore size (Corning, USA). The cells were induced to migrate into $1 \%$ of FBS containing media in 24 well plate. After $48 \mathrm{hr}$ each transwell insert was stained by $1 \%$ crystal violet and destained with $10 \%$ acetic acid. The absorbance was measured at $564 \mathrm{~nm}$ using VERSAmax microplate reader (Molecular devices). (C) H23 cells transfected with pAcGFP-HOXA11 were seeded in a 96 well plate, and cell proliferation activity was measured every $24 \mathrm{hrs}$ with MTT assay. $\mathrm{Y}$ axis indicates absorbance measured at $570 \mathrm{~nm}$ using VERSAmax microplate reader (Molecular devices), and the data are presented as mean \pm standard error (SE) of eight experiments. index using immunohistochemistry (Fig. 4B) in the 317 NSCLCs with a median follow-up period of 5.2 years. The relationship between clinicopathological characteristics and HOXA11 hypermethylation is described in Table 1. Hypermethylation of HOXA11 was found in $218(69 \%)$ of 317 patients studied. HOXA11 hypermethylation was not associated with patient age, sex, exposure to tobacco, differentiation, pathologic stage, histology, pathologic stage, and tumor recurrence. However, the Ki-67 proliferation index was significantly different according to the methylation status of HOXA11 (Fig. 4C). The mean of the Ki-67 proliferation index was $28 \%$ and $19 \%$ in tumors with and without hypermethylation of HOXA11, respectively, and the difference was statistically significant $(\mathrm{P}=0.03)$. In addition, HOXA11 hypermethylation was significantly associated with pT stage (Fig. 4D). HOXA11 hypermethylation was noted to occur in $32(51 \%)$ of the 63 patients with pT1 stage, 154 (71\%) of the 216 with pT2 stage, $15(79 \%)$ of the 19 with pT3 stage, and $17(89 \%)$ of the 19 diagnosed with pT4 stage $(\mathrm{P}=0.002)$.

Logistic regression analysis of the data was performed to control for the potential confounding effects of variables such as age, sex, and histology. HOXA11 hypermethylation occurred at a 1.85 times $(95 \%$ confidence interval $[\mathrm{CI}]=1.04-3.29 ; \mathrm{P}=0.04$ ) higher prevalence in $\mathrm{pT} 2$ stage than in $\mathrm{pT} 1$ stage, after adjusting for age and histology. Patients with pT3 stage were 5.47 times $(95 \% \mathrm{CI}=1.18-25.50 ; \mathrm{P}=0.01)$ more likely to show HOXA11 hypermethylation than those with pT1 stage. Finally, the relationships between hypermethylation of HOXA11 and patient's overall survival and recurrencefree survival were analyzed across pathologic stage. However, no association was found between HOXA11 hypermethylation and patient's survival (Figs. 4E and 4F).

\section{DISCUSSION}

HOXA11 encodes a DNA-binding transcription factor, which may regulate gene expression, morphogenesis, and differentiation. HOXA11 hypermethylation has been reported in lung cancer [6-8], but its functional relationship with malignant phenotype in lung cancer has remained elusive. Several examples exist in which homeobox genes impinge on the cell cycle, but it is not clear how HOXA11 hypermethylation contributes to carcinogenesis of lung. In this study, HOXA11 hypermethylation was found at a higher prevalence in squamous cell carcinoma than adenocarcinoma and occurred at approximately 2 to 5 times higher prevalence in pT2-pT4 stage than pT1 stage. HOXA11 hypermethylation was also associated with Ki67 proliferation index in 317 paraffin-embedded tissues, and transfection of pAcGFP-HOXA11 into H23 cells inhibited the migration and proliferation of the cells. These observations suggest that HOXA11 may function as a tumor suppressor by inhibiting cell proliferation and 
migration in lung cancer.

It is not clear what is responsible for $H O X A 11$ hypermethylation in NSCLC. Increased activity of DNA methyltransferase is one of the possible factors responsible for increased susceptibility to aberrant methylation of $\mathrm{CpG}$ island at the promoter region of tumor suppressor genes $[15,16]$. Smoking is known to increase the activity of DNA methyltransferase, and thereby induces de novo methylation. Increased levels of DNMT1 were observed in the lung of $\mathrm{A} / \mathrm{J}$ mice exposed to the tobacco specific carcinogen 4-methylnitrosamino-1-(3-pyridyl)-1-butanone (NNK) [17]. In addition, several groups have reported positive relationship between exposure to tobacco smoke and $\mathrm{CpG}$ island hypermethylation in NSCLCs. These observations support that the hypermethylation of $\mathrm{CpG}$ island at a gene may be regulated by smoking [18-20]. Therefore, we analyzed the association between exposure to tobacco smoke and $H O X A 11$ hypermethylation in patients. In addition, to rule out the possibility of agedependent hypermethylation of HOXA11 in NSCLC patients, we analyzed the association between $H O X A 11$ hypermethylation and patient age. However, no association was found between exposure to tobacco smoke or patient age and $H O X A 11$ hypermethylation, irrespective of histology (data not shown). Further study is needed to understand the underlying mechanism of $\mathrm{HOXA11}$ hypermethylation in NSCLC.

DNA methylation and histone deacetylation are known to work synergistically to establish and maintain a repressive chromatin state and to silence gene transcription. In this study, the demethylation and reactivation of $H O X A 11$ in response to a low dose of 5-Aza-dC was detected for the majority of the cell lines but minimally for $\mathrm{H} 226$ and A549 cells (Figs. 2C and 2D). As it is known that histone deacetylase inhibition by TSA facilitates transcriptional reactivation induced by 5-Aza-dC, TSA treatment resulted in slight re-expression of the HOXA11 gene to a level detectable by RT-PCR in A549 cells and by real-time PCR in H226 cells (Figs. 2E and $2 \mathrm{~F}$ ). It was not clear what was responsible for low response of $\mathrm{HOXA11}$ to 5-Aza-dC and TSA in $\mathrm{H} 226$ cells. However, there may be several possibilities. First, the patterns of alterations of gene expression induced by different classes of HDACIs are known to be different in various transformed cells. Accordingly, TSA might not be effective in leading to a more relaxed chromatin conformation in $\mathrm{H} 226$ cells, and other classes of HDACIs may be required for the re-expression of HOXA11 in H226 cells. Second, the failure in reversal of repressive transcriptional chromatin modifications following 5-Aza$\mathrm{dC}$ treatment could be due to the short time course of the experiments and low dose of 5-Aza-dC. Finally, HOXA11 in $\mathrm{H} 226$ cells may be inactivated by another mechanism rather than by DNA methylation.

Finally, we analyzed the effect of HOXA11 hypermethylation on patient prognosis. The effect of
A

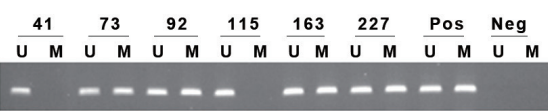

B

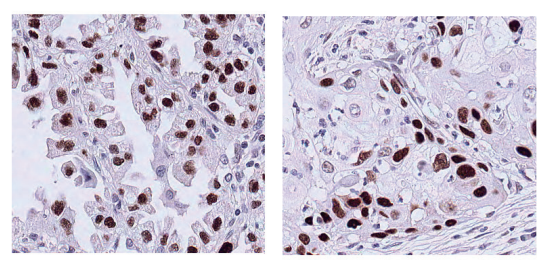

C

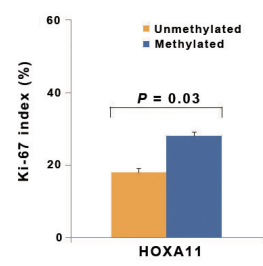

D

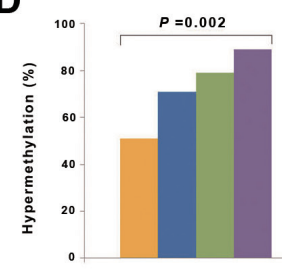

E

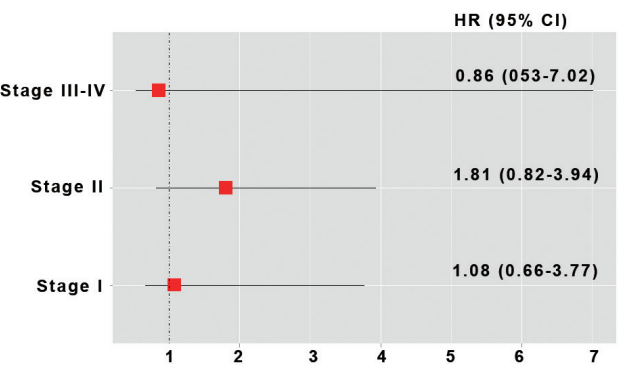

$\mathbf{F}$

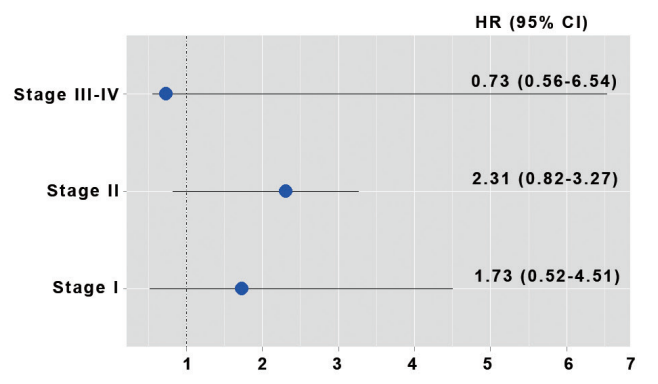

Figure 4: Analysis of $\mathrm{HOXA11}$ hypermethylation in primary non-small cell lung cancer. (A) Promoter hypermethylation of HOXA11 was analyzed in paraffin-embedded tissues from 317 NSCLC patients using methylation-specific PCR. Patient identification numbers are indicated. "Pos" represents the positive controls for the methylated (M) and unmethylated (U) allele. Negative control samples without DNA were included for each PCR. (B) Expression of Ki-67 was analyzed using immunohistochemistry. Figures show representative examples of positive expression of Ki-67 in adenocarcinoma (left) and squamous cell carcinoma (right). (C) Ki-67 proliferation index was compared according to methylation statuses of HOXA11. Error bars indicate standard error. (D) The prevalence of HOXA11 hypermethylation was calculated across pT lesion. HOXA11 hypermethylation showed a significant association with pT lesion $(P=0.002)$. (E \& F) The adjusted hazards ratios (HRs) and 95\% confidence intervals (CIs) for death (E) and recurrence (F) are illustrated across pathologic stage, after controlling for potential confounding factors. 
Table 1: Clinicopathological characteristics $(\mathbf{N}=\mathbf{3 1 7})$

\begin{tabular}{|l|l|l|l|}
\hline \multirow{2}{*}{ Variables } & \multicolumn{2}{|l|}{ HOXA11 hypermethylation } & \multirow{2}{*}{$P$-value } \\
\cline { 2 - 4 } & No (N=99) & Yes (N=218) & \\
\hline Age $^{*}$ & $60 \pm 10$ & $60 \pm 10$ & 0.73 \\
\hline Pack-years & $32 \pm 40$ & $32 \pm 27$ & 0.23 \\
\hline Sex & & & \\
\hline Women & 29 & 53 & \\
\hline Men & 70 & 165 & 0.35 \\
\hline Smoking status & & & \\
\hline Never & 29 & 66 & \\
\hline Former & 12 & 36 & \\
\hline current & 58 & 116 & 0.54 \\
\hline Histology & & & \\
\hline Adenoca & 46 & 78 & \\
\hline Squamous & 44 & 121 & \\
\hline Others & 9 & 19 & 0.17 \\
\hline Differentiation & & & \\
\hline Well & 21 & 33 & \\
\hline Moderately & 40 & 108 & \\
\hline Poorly & 13 & 19 & \\
\hline Undifferentiated & 2 & 5 & 0.24 \\
\hline Stage & & & \\
\hline I & 63 & 124 & \\
\hline II & 25 & 53 & \\
\hline III & 11 & 37 & \\
\hline IV & 0 & 4 & 0.33 \\
\hline Recurrence & & & \\
\hline No & 50 & 124 & \\
\hline Yes & 49 & 94 & 0.29 \\
\hline & & & \\
\hline & & & \\
\hline
\end{tabular}

Abbreviations: Adenoca, adenocarcinoma; Squamous, squamous cell carcinoma;

*Values indicate mean \pm standard deviation

${ }^{\dagger}$ Differentiation data are missing for 76 patients

\$ Based on Fisher's exact test

HOXA11 hypermethylation on overall survival and recurrence-free survival was analyzed in 317 patients. There is no report about the prognostic significance of HOXA11 hypermethylation in lung cancer, and no association was found between HOXA11 hypermethylation and recurrence-free survival or overall survival in this study. However, some have reported prognostic significance of HOXA11 hypermethylation in other types of cancers: HOXA11 hypermethylation is more frequent in recurrent endometrial adenocarcinoma than in non-recurrent endometrial adenocarcinoma and is associated with poor prognosis in early stage endometrial adenocarcinoma. HOXA11 hypermethylation is also known to be strongly associated with the residual tumor after cytoreductive surgery in ovarian cancer, and with poor outcome [9]. In addition, HOXA11 hypermethylation was detected in normal endometrium from premenopausal
Table 2: Logistic regression analysis* of HOXA11 hypermethylation

\begin{tabular}{|c|l|l|l|}
\hline & OR & $95 \%$ CI & P-value \\
\hline Histology & & & \\
\hline Adenoca & 1.00 & & \\
\hline Squamous & 1.71 & $1.01-2.89$ & 0.03 \\
\hline pT & & & \\
\hline pT1 & 1.00 & & \\
\hline pT2 & 1.85 & $1.04-3.29$ & 0.04 \\
\hline pT3 & 5.47 & $1.18-25.50$ & 0.01 \\
\hline pT4 & 5.85 & $1.21-27.28$ & 0.01 \\
\hline
\end{tabular}

Abbreviations: adenoca, adenocarcinoma; squamous, squamous cell carcinoma; OR, odds ratio; CI, confidence interval

* Adjusted for age and sex

ovarian cancer patients, suggesting that HOXA11 hypermethylation can be a predictive marker for ovarian cancer [10]. Based on these observations, it is likely that the effect of HOXA11 hypermethylation on patient survival is tissue-specific.

This study had several limiting actors. First, silencing by DNA methylation usually involves methylbinding domain proteins binding to the DNA and recruiting histone deacetylases (HDACs). Therefore, the DNA binding and HDACs recruiting to the plasmid and the nucleosome assembling on a transfected plasmid needed to be studied for understanding the mechanism underlying transcriptional silencing by HOXA11 hypermethylation. Second, The effect of HOXA11 on cell migration and proliferation was performed in only H23 lung cancer cells. Considering large heterogeneity between established cell lines, it needs further experiments in other cell lines. In addition, HOXA11 was associated with tumor cell migration and proliferation. However, their downstream targets are still unknown; delineation of the target genes regulated by HOXA11 is required. Finally, 500-bp upstream from the ATG translation start codon (Fig. 1B) may be associated with transcriptional downregulation by HOXA11 hypermethylation. Further study is warranted to find critical $\mathrm{CpGs}$ responsible for transcription. In conclusion, the present study suggests that HOXA11 hypermethylation may be involved in the progression of NSCLC through increased cell proliferation and migration.

\section{MATERIALS AND METHODS}

\section{Cell culture}

Six human lung cancer cell lines (H23, H226, H460, H520, H1650, A549), a human bronchial epithelial cell line (HBE135-E6E7), and a human dermal fibroblast 
(HDF) were obtained from the American Type Culture Collection (Manassas, VA). The cells were grown in a designated growth media supplemented with $10 \%$ heatinactivated fetal bovine serum (Hyclone, Logan, UT) and $1 \%$ antibiotic-antimycotic (Gibco, New York, NY), and were maintained at $37^{\circ} \mathrm{C}$ in an atmosphere of $5 \% \mathrm{CO} 2$.

\section{Tissue samples}

Formalin-fixed paraffin-embedded tumor tissues were collected from 317 NSCLC patients who underwent curative surgical resection between August 1994 and November 2011 at the Department of Thoracic and Cardiovascular Surgery, Samsung Medical Center, Seoul, Korea. Post-operative follow-up for survival or recurrence was conducted as previously described [2]. The pathological stage of each specimen was determined according to the guidelines of the AJCC TNM staging system [21]. Written informed consent for use of tissues resected, as approved by the Institutional Review Board at the Center, was obtained from each patient prior to surgery.

\section{Genomic DNA extraction and sodium bisulfite modification}

Genomic DNA from cultured cells and paraffinembedded tissues was extracted using the QIAamp DNA Mini Kit (Qiagen, Hilden, Germany) and DNeasy Tissue kit (Qiagen, Valencia, CA), respectively, according to the manufacturer's protocols. One microgram of genomic DNA from each sample was modified with sodium bisulfite using the EZ DNA Methylation-Gold Kit (ZYMO Research, Irvine, CA) according to the manufacturer's instructions. Areas containing at least $75 \%$ or more of neoplastic cells in the paraffin-embedded tissues were used in this study.

\section{Quantitative Analysis of methylation using EpiTYPER}

Methylation statuses of $90 \mathrm{CpGs}$ at the promoter region of $H O X A 11$ were evaluated in six lung cancer cell lines, HBE135-E6E7 cells, and HDF cells by using the EpiTYPER $^{\mathrm{TM}}$ (Sequenom, San Diego, CA); methylation primers (Supplementary Table S1) for bisulfite-converted DNA were designed using EpiDesigner software (www. epidesigner.com). Following PCR amplification, free nucleotides were inactivated by shrimp alkaline phosphatase, and amplicons were transcribed in vitro, cleaved by RNaseA, and subjected to MALDI-TOF Mass Spectrometry to determine methylation status of the CpGs. EpiTYPER $^{\mathrm{TM}}$ software (version 1.0) was used to analyze the results.

\section{Analysis of $H O X A 11$ mRNA}

The mRNA level of $H O X A 11$ was analyzed using RT-PCR or quantitative real-time PCR. Total RNA was extracted from cultured cells using RNeasy Mini kit (Qiagen, German), and cDNA was synthesized using the SuperScript ${ }^{\mathrm{TM}}$ III First-Strand Synthesis System for use with the RT-PCR (Invitrogen) kit, according to the manufacturer's instructions. RT-PCR was carried out in a tube containing $0.5 \mu \mathrm{g}$ of total RNA and HOXA11specific primers at a final concentration of $0.6 \mu \mathrm{M}$ using a one step RT-PCR kit (Qiagen, Valencia, CA), according to the manufacturer's protocols. PCR products were quantitated with the GeneAmp PCR System 2700 (Applied Biosystems, Foster City, CA). Quantitative realtime PCR was performed with SYBR Green PCR Master Mix (QIAGEN, Germany) on a LightCycler ${ }^{\mathrm{r}} 480$ RealTime PCR System (Roche, Germany). The experiments were performed in triplicate, and results were expressed as mean and standard deviation of the three independent experiments. GAPDH (Glyceraldehyde-3-phosphate dehydrogenase) was used as an internal control to normalize equal amounts of RNA. Primers for RT and real-time PCR were described in Supplementary Table S2.

\section{Western blot analysis}

For Western blot analysis, cells were lysed in PROPREP protein extraction solution (iNtRON Biotechnology, Korea), and protein concentrations were determined using the BCA Protein Assay Kit (Pierce, USA). Fifty $\mu \mathrm{g}$ of protein was separated on NuPAGE ${ }^{\circledR} 4-12 \%$ BisTris Gel (Invitrogen, Carlsbad, CA), and the proteins were electroblotted to polyvinylidene fluoride (PVDF) membranes (Millipore, MA). After blocking with $1 \%$ Tween 20-Tris-buffered saline containing 5\% nonfat dry milk, the membrane was incubated overnight at $4{ }^{\circ} \mathrm{C}$ with HOXA11 antibody (Abcam, England). Membrane was washed three times for 15 minutes with blocking solution and incubated with secondary antibody (Southern biotech, USA) for 2 hours at room temperature. Membrane was washed again three times for 15 minutes with blocking solution and incubated with WEST-ZOL (plus) chemiluminescence reagent (iNtRON Biotechnology, Korea) for 5 minutes and exposed to film (Kodak BioMax light film, USA).

\section{TSA and 5-Aza-dC treatment of cells}

Cells were incubated with $10 \mu \mathrm{M}$ 5-Aza-2'deoxycytidine (5-Aza-dC; Sigma Aldrich, St. Louis, MO) for $72 \mathrm{~h}$ or were co-incubated with $0.5 \mu \mathrm{M}$ trichostatin A (TSA) for the final $24 \mathrm{~h}$ of those $72 \mathrm{~h}$. After $72 \mathrm{~h}$ of culture, cells were harvested and washed in ice-cold 
PBS. Genomic DNA and mRNA were then isolated and subjected to analysis of the methylation status by EpiTYPER $^{\mathrm{TM}}$ assay and methylation-sensitive highresolution melt (MS-HRM) assay and of the expression level by RT-PCR and quantitative real-time PCR.

\section{Methylation-sensitive high-resolution melt (MS- HRM) assay}

Methylation statuses of $H O X A 11$ in response to 5-Aza-dC were analyzed using the MS-HRM assay in six lung cancer cell lines, and $10 \mathrm{ng}$ of bisulfite-treated genomic DNA was amplified for the assay. Primers were designed using SEQUENOM EpiDesigner software (Supplementary Table S3), and MS-HRM was performed on LC-480 real-time PCR machine and analyzed by Gene Scanning software (Roche, Swiss).

\section{Transient transfection of $\mathrm{HOXA11}$}

To determine the effect of $H O X A 11$ on migration and proliferation, $\mathrm{H} 23$ cells were transfected with $1 \mu \mathrm{g}$ of HOXA11 using Lipofectamin ${ }^{\mathrm{TM}} 2000$ (Life Technologies, Carlsbad, CA). Full-length HOXA11 cDNA (Clone number: IRATp970D0771D) was purchased from Source BioScience (Nottingham, UK). pAcGFP-HOXA11 constructs were generated by cloning HOXA11 cDNA inframe into a pAcGFP1-C1 vector (CLONTECH, Oxford, $\mathrm{UK}$ ). For the migration assay, $\mathrm{H} 23$ cells were seeded in six well plates at a concentration of $1 \times 10^{5}$ cells and incubated overnight to approximately $60-80 \%$ confluence. They were then transfected with $1 \mu \mathrm{g}$ of a pAcGFP1-C1 constitutively expressing $H O X A 11$ or with an empty vector using Lipofectamin ${ }^{\mathrm{TM}} 2000$ (Life Technologies, Carlsbad, $\mathrm{CA}$ ) according to the manufacturer's instructions.

After $48 \mathrm{~h}$ of transfection, the expression of $\mathrm{HOXA11}$ was confirmed by western blot analysis according to a standard protocol using primary antibodies directed against GFP (sc-9996; Santa Cruz Biotechnology, CA, USA). Migration assay was performed using transwell migration chambers $(6.5 \mathrm{~mm}$ diameter polycarbonate membranes, $8 \mu \mathrm{m}$ pore size) (Corning Costar, Lowell, MA) according to the manufacturer's instructions. The absorbance was measured at $564 \mathrm{~nm}$ using VERSAmax microplate reader (Molecular devices). For proliferation assay, H23 cells were seeded into 96-well plates at a density of $1 \times 10^{3}$ after transfection, and cell proliferation was measured by MTT assay every $24 \mathrm{hrs}$.

\section{Immunohistochemistry of Ki-67}

Ki-67 expression status in formalin-embedded paraffin-embedded tissue samples was assessed as described previously [22]. The fraction of Ki-67-positive cells (Ki-67 proliferation index) was defined as the proportion of the nuclear staining of the tumor cells that were positively stained with a monoclonal anti-Ki-67 antibody (clone MIB-1, DAKO, Carpinteria, CA).

\section{Methylation-specific polymerase chain reaction (MSP)}

The methylation statuses of HOXA11 in the 317 formalin-fixed paraffin-embedded tissues were determined using methylation-specific PCR (MSP), as described previously (2). For MSP, two sets of primers were used to amplify methylated and unmethylated allele, respectively. The primer sequences are listed in Supplementary Table S4.

\section{Statistical Analysis}

The differences in clinicopathological characteristics and methylation status of $H O X A 11$ were analyzed using the t-test (or Wilcoxon rank sum test) and the Chisquared test (or Fisher's exact test) for continuous and categorical variables, respectively. Survival estimate for HOXA11 hypermethylation on survival was calculated using Kaplan-Meier survival curves, and the statistical comparison of survival curves between the two groups was evaluated using a log-rank test. The hazard ratios of independent predictor variables, after adjusting for potential confounders, were determined using the Cox proportional hazards regression model.

\section{ACKNOWLEDGEMENTS}

The authors wish to thank Eun-Kyung Kim and Jin-Hee Lee for data collection and management, and Hoon Suh and Seo Kyu Park for sample collection. This work was supported by grants from the National Cancer Center (NCC 1110140-1 and 1110100-2), the Basic science research Program through the National Research Foundation of Korea (NRF) funded by the Ministry of Education, Science and Technology (2011-0026037), and the National Research Foundation of Korea (NRF) grant funded by the Korea government (MEST) (No. 20110029138), Republic of Korea.

\section{REFERENCES}

1. Jemal A, Siegel R, Ward E, Hao Y, Xu J, Murray T, Thun MJ. Cancer statistics, 2008. CA Cancer J Clin. 2005; 58: 71-96.

2. Kim JS, Kim JW, Han J, Shim YM, Park J, Kim DH. Cohypermethylation of p16 and FHIT promoters as a prognostic factor of recurrence in surgically resected stage I non-small cell lung cancer. Cancer Res. 2006; 66: 4049- 
4054.

3. Golpon HA, Geraci MW, Moore MD, Miller HL, Miller GJ, Tuder RM, Voelkel NF. HOX genes in human lung: altered expression in primary pulmonary hypertension and emphysema. Am J Pathol. 2001; 158: 955-966.

4. Krumlauf R. Hox genes in vertebrate development. Cell. 1994; 78: 191-201.

5. Rauch T, Wang Z, Zhang X, Zhong X, Wu X, Lau SK, Kernstine KH, Riggs AD, Pfeifer GP. Homeobox gene methylation in lung cancer studied by genome-wide analysis with a microarray-based methylated $\mathrm{CpG}$ island recovery assay. Proc Natl Acad Sci U S A. 2007; 104: $5527-5532$.

6. Bibikova M, Lin Z, Zhou L, Chudin E, Garcia EW, Wu B, Doucet D, Thomas NJ, Wang Y, Vollmer E, Goldmann T, Seifart C, Jiang W, Barker DL, Chee MS, Floros J, et al. High-throughput DNA methylation profiling using universal bead arrays. Genome Res. 2006; 16: 383-393.

7. Olaussen KA, Soria JC, Park YW, Kim HJ, Kim SH, Ro JY, André F, Jang SJ. Assessing abnormal gene promoter methylation in paraffin-embedded sputum from patients with NSCLC. Eur J Cancer. 2002; 41: 2112-2119.

8. Nelson HH, Marsit CJ, Christensen BC, Houseman EA, Kontic M, Wiemels JL, Karagas MR, Wrensch MR, Zheng S, Wiencke JK, Kelsey KT. Key epigenetic changes associated with lung cancer development: Results from dense methylation array profiling. Epigenetics. 2012; 7: 559-566.

9. Fiegl H, Windbichler G, Mueller-Holzner E, Goebel G, Lechner M, Jacobs IJ, Widschwendter M. HOXA11 DNA methylation--a novel prognostic biomarker in ovarian cancer. Int J Cancer. 2008; 123: 725-729.

10. Widschwendter M, Apostolidou S, Jones AA, Fourkala EO, Arora R, Pearce CL, Frasco MA, Ayhan A, Zikan M, Cibula D, Iyibozkurt CA, Yavuz E, Hauser-Kronberger C, Dubeau L, Menon U, Jacobs IJ. HOXA methylation in normal endometrium from premenopausal women is associated with the presence of ovarian cancer: a proof of principle study. Int J Cancer. 2009; 125: 2214-2218.

11. Martinez R, Martin-Subero JI, Rohde V, Kirsch M, Alaminos M, Fernandez AF, Ropero S, Schackert G, Esteller M. A microarray-based DNA methylation study of glioblastoma multiforme. Epigenetics. 2009; 4: 255-264.

12. Bennett LB, Schnabel JL, Kelchen JM, Taylor KH, Guo J, Arthur GL, Papageorgio CN, Shi H, Caldwell CW. DNA hypermethylation accompanied by transcriptional repression in follicular lymphoma. Genes Chromosomes Cancer. 2009; 48: 828-841.

13. Whitcomb BP, Mutch DG, Herzog TJ, Rader JS, Gibb RK, Goodfellow PJ. Frequent HOXA11 and THBS2 promoter methylation, and a methylator phenotype in endometrial adenocarcinoma. Clin Cancer Res. 2003; 9: 2277-2287.

14. Apostolidou S, Hadwin R, Burnell M, Jones A, Baff D, Pyndiah N, Mould T, Jacobs IJ, Beddows S, Kocjan G,
Widschwendter M. DNA methylation analysis in liquidbased cytology for cervical cancer screening. Int J Cancer. 2009; 125: 2995-3002.

15. Fatemi M, Hermann A, Gowher H, Jeltsch A. Dnmt3a and Dnmt1 functionally cooperate during de novo methylation of DNA. Eur J Biochem. 2001; 269: 4981-4984.

16. Rhee I, Bachman KE, Park BH, Jair KW, Yen RW, Schuebel KE, Cui H, Feinberg AP, Lengauer C, Kinzler KW, Baylin SB, Vogelstein B. DNMT1 and DNMT3b cooperate to silence genes in human cancer cells. Nature. 2001; 416: 552-556.

17. Belinsky SA, Nikula KJ, Baylin SB, Issa JP. Increased cytosine DNA-methyltransferase activity is target-cellspecific and an early event in lung cancer. Proc Natl Acad Sci U S A. 1996; 93: 4045-4050.

18. Swafford DS, Middleton SK, Palmisano WA, Nikula KJ, Tesfaigzi J, Baylin SB, Herman JG, Belinsky SA. Frequent aberrant methylation of p16INK4A in primary rat lung tumors. Mol Cell Biol. 1997; 17: 1366-1374.

19. Kim DH, Nelson HH, Wiencke JK, Zheng S, Christiani DC, Wain JC, Mark EJ, Kelsey KT. p16INK4a and histologyspecific methylation of $\mathrm{CpG}$ islands by exposure to tobacco smoke in non-small cell lung cancer. Cancer Res. 2001; 61: 3419-3424.

20. Belinsky SA, Palmisano WA, Gilliland FD, Crooks LA, Divine KK, Winters SA, Grimes MJ, Harms HJ, Tellez CS, Smith TM, Moots PP, Lechner JF, Stidley CA, Crowell RE. Aberrant promoter methylation in bronchial epithelium and sputum from current and former smokers. Cancer Res. 2001; 62: 2370-2377.

21. Edge SB, Byrd DR, Compton CC, Fritz AF, Greene FL, Trotti A. American Joint Committee on Cancer. In: AJCC Cancer Staging Manual. (7th edn), New York: Springer; 2010. p 253-270.

22. Kim JS, Han J, Shim YM, Park J, Kim DH. Aberrant methylation of $\mathrm{H}$-cadherin (CDH13) promoter is associated with tumor progression in primary nonsmall cell lung carcinoma. Cancer. 2005; 104: 1825-1833. 